\title{
Pengaruh Preventif Multimodal Analgesia Terhadap Dinamika Kadar Il - 1及, Intensitas Nyeri Pada Pascabedah Laparotomi Ginekologi
}

\section{The Effect Of Preventive Multimodal Analgesia On Il-1及 Level And Pain Intensity In Post Gynecologic Laparotomy}

\author{
Muhammad Hisyam*, Muhammad Ramli*, Burhanuddin Bahar** \\ *Bagian Anestesiologi, Perawatan Intensif dan Manajemen Nyeri, Fakultas Kedokteran,Universitas Hasanuddin, Makassar \\ **Bagian Ilmu Kesehatan Masyarakat, Fakultas Kedokteran, Universitas Hasanuddin, Makassar
}

\section{ABSTRACT}

Background: Postoperative pain is an extremely important issue facing patients postoperative. Although our knowledge of the mechanisms of postoperative pain has been a lot of progress, but not yet optimal management of postoperative pain and still often neglected. Interleukin (IL) $1 \beta$ is one of the proinflammatory cytokine levels will rise when the inflammatory process.

Objective: This study aims to compare the level of $I L-1 \beta$ between the group receiving epidural bupivacaine $0.125 \%$ combined with $40 \mathrm{mg}$ parecoxibe and the one treated with epidural bupivacaine $0.125 \%$ used as multimodal preventive analgesia after gynecological laparotomy operation.

Method: A randomised double blind experiment was administered to 50 patients with physical status (ASA PS) II who would experience gynecological laparotomy procedure with epidural anesthesia. The study subjects were divided into two treatment groups, one with a combination between epidural bupivacaine 0,125\% and parecoxib $40 \mathrm{mg}(n=25)$ and the other one with a placebo combination with $\mathrm{NaCl}$ $0,9 \%(n=25)$. Each would have epidural anesthesia during operation and the postoperative analgesia. Thirty-five minutes before surgery, the patients' blood sample was taken for IL-1 $\beta$ level measurement and so was at 2 and 24 hours after surgery. Statistical analysis used statistical software, Mann-Whitney U test and Levane test.

Result: Average level of $I L-1 \beta$ in parecoxib group was $1,05 \pm 1,25 \mathrm{pg} / \mathrm{ml}$ preoperatively, $1,24 \pm 1,54 \mathrm{pg} / \mathrm{ml} 2$ hours postoperative and 1,82 $\pm 2,16 \mathrm{pg} / \mathrm{ml} 24$ hours postoperative. In control group, IL-1 $\beta$ level was $1,65 \pm 1,69 \mathrm{pg} / \mathrm{ml}$ preoperatively,

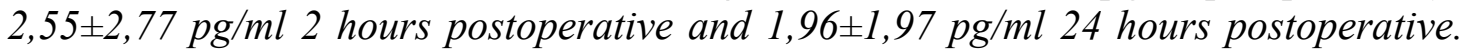
Average NRS score between resting and moving was not significantly different at 2, 12 and 24 hours postoperative $(p>0,05)$.

Conclusion: Combination of epidural bupivacaine 0,125\% with parecoxibe $40 \mathrm{mg}$ decrease IL-1 $\beta$ level at 2 hour after the surgery.

Keywords: Bupivacaine, Epidural , IL-1 $\beta$, Laparotomy Gynecology, Parecoxib.

\section{ABSTRAK}

Latar Belakang: Nyeri pascabedah merupakan permasalahan sangat penting yang dihadapi pasien pascabedah. Meskipun pengetahuan kita tentang mekanisme nyeri pascabedah sudah mengalami banyak kemajuan, namun pengelolaan nyeri 
pascabedah belum optimal dan masih sering terabaikan. Interleukin (IL) $1 \beta$ adalah salah satu sitokin proinflamasi yang kadarnya akan meningkat bila terjadi proses inflamasi.

Tujuan: Penelitian ini bertujuan untuk membandingkan kadar IL-1 $\beta$, skala NRS, pada kelompok yang mendapatkan epidural bupivakain 0,125\% kombinasi parecoxib $40 \mathrm{mg}$ dengan kelompok yang mendapatkan epidural bupivakain 0,125\% yang digunakan sebagai multimodal preventif analgesia pascabedah laparotomi ginekologi.

Metode: Penelitian eksperimental dilakukan secara acak pada 50 pasien dengan status fisik (ASA PS) II yang akan menjalani prosedur laparotomi ginekologi dengan anestesi epidural. Subyek penelitian dibagi dalam dua kelompok perlakuan, yakni kelompok pertama dengan kombinasi parecoxib $40 \mathrm{mg}(n=25)$ dan kelompok kedua dengan kombinasi plasebo $\mathrm{NaCl}$ 0,9\% (n=25). Kedua kelompok tersebut mendapatkan anestesi epidural selama operasi dan sebagai analgesia pascabedah. Pengambilan sampel darah pasien dilakukan 35 menit sebelum pembedahan untuk pengukuran kadar IL-1 $\beta$, selanjutnya dilakukan pada 2 jam dan 24 jam pascabedah. Analisis statistik menggunakan uji Mann-Whitney $U$ dan Levane test.

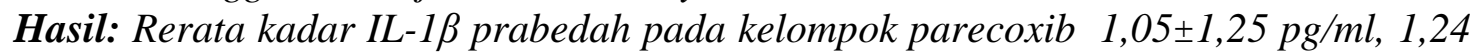
$\pm 1,54 \mathrm{pg} / \mathrm{ml}$ untuk 2 jam pascabedah dan 1,82 $\pm 2,16 \mathrm{pg} / \mathrm{ml}$ pada 24 jam pascabedah.

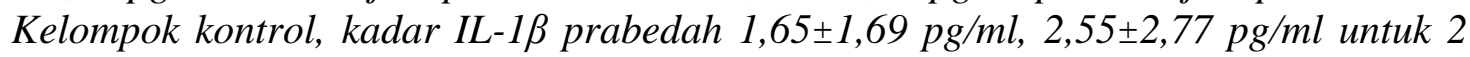

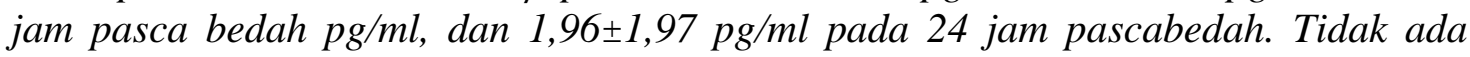
perbedaan bermakna rerata skor NRS diam dan bergerak 2 jam, 12 jam, dan 24 jam pascabedah diantara kedua kelompok sampel $(p>0,05)$.

Kesimpulan: Kombinasi epidural bupivakain 0,125\% dengan parecoxib $40 \mathrm{mg}$ dapat menurunkan kadar IL-1 $\beta$ pada 2 jam pascabedah.

Kata kunci: Bupivakain, Epidural, IL-1 $\beta$, Laparotomi Ginekologi, Parecoxib

\section{PENDAHULUAN}

Nyeri pascabedah merupakan permasalahan sangat penting yang dihadapi pasien pascabedah. Nyeri pascabedah akan mempengaruhi sistem kardiovaskuler, respirasi dan endokrin. Meskipun pengetahuan kita tentang mekanisme nyeri pascabedah sudah mengalami banyak kemajuan, namun pengelolaan nyeri pascabedah belum optimal dan masih sering terabaikan. Suatu survey yang dilakukan Apfelbaum pada tahun 2003, menemukan bahwa sekitar $82 \%$ pasien masih mengalami nyeri akut, $47 \%$ diantaranya dengan nyeri sedang dan $40 \%$ dengan nyeri berat dan sangat berat. ${ }^{1}$
Respon inflamasi terhadap trauma pascabedah dapat menginduksi respon stres neuroendokrin, yang pertama pada jaringan inflamasi perifer yang dapat di hambat oleh anestesi lokal dan cyclooxygenase (COX-2) inhibitor. Jalur yang kedua adalah sinyal humoral yang berasal dari jaringan inflamasi perifer menyebabkan produksi sitokin seperti Interleukin-1 $\beta$ (IL- $\beta)$, IL-2, IL-6 dan tumor necrosing factor (TNF) yang akan menginduksi penyebaran dan peningkatan COX-2 dan sintesa prostaglandin yang berada di central nervous system (CNS). Hal ini tidak dapat dihambat dengan efektif oleh 
anestesi regional, namun pemberian COX-2 inhibitor yang bekerja sentral akan menekan produksi ini. ${ }^{2}$ Sekarang ini the American Society of Anesthesiology Task Force on Acute Pain Management dan the Agency for Health Care research and Quality menganjurkan penggunaan pendekatan multimodal analgesia dalam penangan nyeri akut. ${ }^{3}$

Ahmad pada tahun 2012, dalam sebuah penelitian menunjukkan bahwa analgesia preemptif epidural memiliki rasio sitokin proinflamasi/anti-inflamasi lebih rendah dibanding kelompok kontrol namun tidak berbeda bermakna, dan membuktikan bahwa epidural preemptif tidak dapat menekan sensitisasi sentral melalui jalur humoral. ${ }^{4}$ Samad dkk. pada tahun 2002, melalui penelitiannya menyatakan bahwa, epidural hanya dapat menghambat jalur neural dan tidak dapat menghambat jalur humoral. ${ }^{5}$

Beilin dkk pada tahun 2003, melakukan penelitian mengenai preemptif analgesia dengan menggunakan epidural terhadap skor nyeri dan produksi sitokin, membuktikan bahwa penggunaan epidural preemptif dapat menurunkan skor nyeri dan produksi IL -1 $\beta$, IL-6, IL-1ra secara signifikan kurang meningkat dibandingkan kelompok kontrol. ${ }^{6}$

Pembedahan histerektomi merupakan salah satu jenis pembedahan ginekologi yang paling banyak dilakukan, dimana nyeri pascabedah pada prosedur ini melibatkan nyeri somatik dan viseral. Nyeri kronik pasca histerektomi merupakan masalah klinis yang besar, 5$30 \%$ pasien yang menjalani histerektomi masih merasakan nyeri setelah 1 tahun pascabedah. ${ }^{7}$

Barton dkk dalam penelitiannya mengungkapkan bahwa injeksi parecoxib sama efektifnya dengan ketorolak dalam menurunkan nyeri pascabedah pada operasi laparatomi ginekologi. ${ }^{8} \mathrm{Ng}$ dalam penelitiannya tentang penggunaan parecoxib pada histerektomi total abdominal merekomendasikan penggunaan parecoxib $40 \mathrm{mg}$ iv sebagai sparing morfin. ${ }^{9}$ Malan menyatakan injeksi parecoxib intramuskular $40 \mathrm{mg}$ sama efektifnya dengan morfin $12 \mathrm{mg}$ pada pembedahan laparatomi ginekologi. ${ }^{10}$

Naito dkk, mengungkapkan bahwa blok epidural tidak dapat mencegah respon hormon stres pada pembedahan abdomen bagian atas. ${ }^{11}$ Aida dkk, menyatakan bahwa keefektifan dari analgetik yang diberikan dipengaruhi oleh jenis pembedahan, dimana analgesia preemptif tidak efektif pada pembedahan yang melibatkan organ viseral dan peritoneum (laparotomi). ${ }^{12}$

Uraian tersebut merupakan dasar dari penelitian ini, namun dari seluruh penelitian mengenai analgesia preemptif dan preventif yang dipublikasikan belum pernah dilakukan kombinasi teknik analgesia epidural dengan menggunakan bupivakain $0,125 \%$ dan fentanyl dengan parecoxib $40 \mathrm{mg}$ iv 
pada pembedahan laparotomi ginekologi dengan menilai kadar IL-1 $\beta$ dan intensitas nyeri.

\section{METODE}

Penelitian ini dilakukan di kamar bedah RS Wahidin Sudirohusodo Makassar selama \pm 2 (dua) bulan (Juni 2013- Juli 2013). Penelitian ini merupakan uji klinis acak tersamar ganda (consecutive random sampling).

Populasi penelitian adalah pasien yang menjalani prosedur laparotomi ginekologi di ruang bedah sentral RS Wahidin Sudirohusodo dan jejaringnya selama masa penelitian. Sampel sebanyak 50 orang yang dipilih secara acak yang telah memenuhi kriteria inklusi yaitu: pasien yang menjani prosedur laparotomi ginekologi dengan prosedur epidural anestesi, ASA PS 12, usia $18-60$ tahun, IMT $18-25 \mathrm{~kg} /$ $\mathrm{cm}^{2}$, tidak mempunyai penyakit jantung, obesitas, hati, gangguan ginjal, osteoartritis, tidak mengkonsumsi antibiotik dan menggunakan kortikosteroid lama serta bersedia untuk mengikuti penelitian ini dan menandatangani informed consent yang telah dikeluarkan oleh Komisi Etik Fakultas Kedokteran Universitas Hasanuddin.

Pengumpulan data dilakukan oleh kami dibantu oleh peserta PPDS anestesiologi Unhas di RS Wahidin Sudirohusodo. Data pasien mengenai pengambilan darah pada jam ke 0,2 jam dan 24 jam pascabedah. dicatat pada lembar pengamatan selama periode pengamatan.

Data yang diperoleh diolah dan hasilnya ditampilkan dalam bentuk narasi, tabel atau grafik. Analisis statistik yang digunakan piranti lunak statistik yaitu sebagai berikut: (1) Kadar IL-1 $\beta$ dengan uji Mann-Whitney $U$ (2) Velocity menggunakan Levane test (3) Nilai NRS dengan uji Mann-Whitney $U$ (4) Kebutuhan analgetik diuji dengan uji Mann-Whitney $U$.

\section{HASIL}

\section{Karakteristik Pasien}

Dari Tabel 1 dan Tabel 2, dapat dilihat bahwa tidak didapatkan perbedaan bermakna dari data demografi pada kedua kelompok penelitian. Sehingga karakteristik dari 50 sampel penelitian dinyatakan homogen. Dari Tabel 1, karakteristik menurut umur, IMT , lama operasi, dan konsumsi anestesi lokal, dari 50 sampel penelitian dinyatakan homogen dengan nilai $p>0,05$. Terlihat bahwa untuk kategori umur didapatkan nilai rerata umur untuk kelompok Parecoxib $(44,2 \pm 5,1)$ tahun dan kelompok kontrol $(44,8 \pm 5,6)$ tahun dengan nilai $(p=0,733)$, kategori IMT didapatkan nilai rerata IMT untuk kelompok Parecoxib $(21,7 \pm 0,9) \mathrm{kg} / \mathrm{m}^{2}$ dan kelompok kontrol $(21,4 \pm 0,9) \mathrm{kg} / \mathrm{m}^{2}$ dengan nilai $(\mathrm{p}=0,184)$, kategori durasi operasi didapatkan nilai rerata pada kelompok Parecoxib (101,6 \pm 15,5) menit dan pada kelompok kontrol 
Tabel 1. Perbandingan Umur, IMT, Durasi dan Anestesi Lokal menurut Kelompok

\begin{tabular}{lllccc}
\hline & Kelompok & $\mathrm{N}$ & Rerata & Simpang Baku & P \\
\hline Umur & Parecoxib & 25 & 44,2 & 5,1 & 0,733 \\
\cline { 2 - 5 } & Kontrol & 25 & 44,8 & 5,6 & \\
\hline IMT & Parecoxib & 25 & 21,7 & 0,9 & 0,184 \\
\cline { 2 - 5 } & Kontrol & 25 & 21,4 & 0,9 & 0,251 \\
\hline Durasi & Parecoxib & 25 & 101,6 & 15,5 & \\
\cline { 2 - 5 } & Kontrol & 25 & 106,6 & 18,4 & 0,743 \\
\hline Anestesi Lokal & Parecoxib & 25 & 115,6 & 19,2 & \\
\cline { 2 - 5 } & Kontrol & 25 & 117,4 & 17,9 & \\
\hline
\end{tabular}

Data disajikan dalam bentuk nilai rerata,simpang baku dan nilai p diuji dengan Uji Mann Whitney- $U$, bermakna jika p $<0,05$

Tabel 2. Sebaran Diagnosis menurut Kelompok

\begin{tabular}{|c|c|c|c|c|c|}
\hline & & & \multicolumn{2}{|c|}{ Kelompok } & \multirow[b]{2}{*}{ Total } \\
\hline & & & Parecoxib & Kontrol & \\
\hline \multirow[t]{4}{*}{ Diagnosis } & Tumor Ovarium & $\mathrm{N}$ & 8 & 11 & 19 \\
\hline & & $\%$ & $32,0 \%$ & $44,0 \%$ & $38,0 \%$ \\
\hline & Tumor Uterus & $\mathrm{N}$ & 17 & 14 & 31 \\
\hline & & $\%$ & $68,0 \%$ & $56,0 \%$ & $62,0 \%$ \\
\hline \multirow[t]{2}{*}{ Total } & & $\mathrm{N}$ & 25 & 25 & 50 \\
\hline & & $\%$ & $100,0 \%$ & $100,0 \%$ & $100,0 \%$ \\
\hline
\end{tabular}

Data diuji dengan uji Chi Square $(\mathrm{p}=0,382)$, bermakna bila $\mathrm{p}<0.05$ 
$(106,6 \pm 18,4)$ dengan nilai $(p=0,251)$, kategori konsumsi anestesi lokal didapatkan nilai rerata konsumsi anestesi lokal pada kelompok Parecoxib $(115,6 \pm 19,2) \mathrm{mg}$ dan pada kelompok kontrol $(117,4 \pm 17,9) \mathrm{mg}$ dengan nilai $(\mathrm{p}=0,743)$. Semua pasien yang diikutkan termasuk kategori ASA PS II.

Pada Tabel 2, karakteristik menurut diagnosa prabedah dimana pada kelompok Parecoxib, pasien dengan diagnosa tumor ovarium sebanyak 8 pasien $(32 \%)$, tumor uterus 17 pasien (68\%). Pada kelompok kontrol, pasien dengan diagnosa tumor ovarium sebanyak 11 pasien (44\%), tumor uterus $14(56 \%)$.

\section{Kadar IL-1及}

Untuk mengamati perbandingan kadar IL-1 $\beta$ sebagai respon inflamasi, dilakukan pengukuran kadar IL-1 $\beta$ secara serial, yaitu pada saat prabedah, 2 jam dan 24 jam pascabedah. Hasil analisa dari pengukuran kadar IL-1 $\beta$ pada kedua kelompok dapat dilihat pada Tabel 3. Tabel 3 menunjukkan bahwa kadar IL-1 $\beta$ prabedah pada kelompok parecoxib memiliki nilai rata-rata 1,05 $\mathrm{pg} / \mathrm{ml}$ dengan nilai simpang baku $\pm 1,25$ $\mathrm{pg} / \mathrm{ml}$, untuk 2 jam pascabedah adalah $1,24 \pm 1,54 \mathrm{pg} / \mathrm{ml}$ dan 24 jam pascabedah adalah 1,82 $\pm 2,16 \mathrm{pg} / \mathrm{ml}$. Pada kelompok kontrol, kadar IL-1 $\beta$ prabedah adalah 1,65 $\pm 1,69 \mathrm{pg} / \mathrm{ml}$, untuk 2 jam pasca bedah adalah 2,55 $\pm 2,77 \mathrm{pg} / \mathrm{ml}$, dan pada 24 jam pascabedah $1,96 \pm 1,97$. Pada tabel 3 dapat terlihat bahwa antara kedua kelompok, terdapat perbedaan yang bermakna kadar IL-1 $\beta$ pada 2 jam pascabedah $(\mathrm{p}<0,05)$, sementara kadar IL-1 $\beta$ pra bedah dan 24 jam pascabedah tidak terdapat perbedaan yang bermakna ( $>>0,05)$.

\section{Intensitas nyeri}

Intensitas nyeri pada penelitian ini diamati dengan menggunakan NRS saat istirahat maupun bergerak/batuk pada saat 2 jam, 12 jam, dan 24 jam pascabedah, namun dalam rentang 24 jam pascabedah bila NRS > 4 akan diberikan tambahan analgetik. Pada Tabel 4 didapatkan bahwa tidak ada perbedaan bermakna rerata skor NRS diam 2 jam, 12 jam, dan 24 jam pascabedah diantara kedua kelompok sampel $(\mathrm{p}>0,05)$.

Pada Tabel 5 didapatkan bahwa tidak ada perbedaan bermakna rerata skor NRS bergerak 2 jam, 12 jam, dan 24 jam pascabedah diantara kedua kelompok sampel $(\mathrm{p}>0,05)$.

\section{PEMBAHASAN}

Penelitian ini dilakukan untuk melihat pengaruh penggunaan kombinasi parecoxib $40 \mathrm{mg}$ IV dengan analgesia epidural $0,125 \%$ dengan ajuvan fentanyl terhadap kadar IL-1 $\beta$ dan intensitas nyeri pascabedah laparatomi ginekologi.

Pada penelitian ini diperoleh hasil kadar IL-1 $\beta$ mengalami perubahan yang signifikan pada kelompok parecoxib 


\section{Jurnal Anestesiologi Indonesia}

Tabel 3. Perbandingan Kadar IL-1 $\beta$ menurut Kelompok

\begin{tabular}{|c|c|c|c|c|c|}
\hline & Kelompok & $\mathrm{N}$ & Rerata & Simpang Baku & $\mathrm{P}$ \\
\hline \multirow[t]{2}{*}{ Kadar IL-1 $\beta$ Awal } & Parecoxib & 25 & 1,05 & 1,25 & \multirow[t]{2}{*}{0,162} \\
\hline & Kontrol & 25 & 1,65 & 1,69 & \\
\hline \multirow{2}{*}{$\begin{array}{l}\text { Kadar IL-1 } \beta \quad 2 \text { Jam pasca } \\
\text { bedah }\end{array}$} & Parecoxib & 25 & 1,24 & 1,54 & \multirow[t]{2}{*}{0,044} \\
\hline & Kontrol & 25 & 2,55 & 2,77 & \\
\hline \multirow{2}{*}{$\begin{array}{l}\text { Kadar IL-1 } \beta 24 \text { Jam } \\
\text { Pascabedah }\end{array}$} & Parecoxib & 25 & 1,82 & 2,16 & \multirow[t]{2}{*}{0,820} \\
\hline & Kontrol & 25 & 1,96 & 1,97 & \\
\hline
\end{tabular}

Data disajikan dalam bentuk nilai rerata,simpang baku dan nilai p diuji dengan Uji Mann Whitney- $U$, bermakna jika $<<0,05$.

Tabel 4. Perbandingan Skor NRS Diam menurut Kelompok

\begin{tabular}{lllccc}
\hline & Kelompok & N & Rerata & Simpang Baku & P \\
\hline NRS Diam awal & Parecoxib & 25 & 0,0 & 0,0 & 1,000 \\
\cline { 2 - 5 } & Kontrol & 25 & 0,0 & 0,0 & \\
\hline NRS Diam 2 Jam & Parecoxib & 25 & 2,0 & 0,3 & 1,000 \\
\cline { 2 - 5 } & Kontrol & 25 & 2,0 & 0,0 & \\
\hline NRS Diam 24 Jam & Parecoxib & 25 & 1,9 & 0,3 & 1,000 \\
\cline { 2 - 5 } & Kontrol & 25 & 1,9 & 0,3 & \\
\hline
\end{tabular}

Data disajikan dalam bentuk nilai rerata,simpang baku dan nilai p diuji dengan Uji Mann-Whitney $\mathrm{U}$, bermakna jika p<0,05.

Tabel 5. Perbandingan NRS Bergerak menurut Kelompok

\begin{tabular}{lllccc}
\hline & Kelompok & N & Rerata & Simpang Baku & p \\
\hline \multirow{2}{*}{ NRS Bergerak awal } & Parecoxib & 25 & 0,0 & 0,0 & 1,000 \\
\cline { 2 - 5 } & Kontrol & 25 & 0,0 & 0,0 & \\
\hline NRS Bergerak 2 Jam & Parecoxib & 25 & 2,9 & 0,4 & 0,967 \\
\cline { 2 - 5 } & Kontrol & 25 & 2,9 & 0,3 & \\
\hline NRS Bergerak 24 Jam & Parecoxib & 25 & 2,1 & 0,4 & 0,106 \\
\hline
\end{tabular}

Data disajikan dalam bentuk nilai rerata,simpang baku dan nilai p diuji dengan Uji Mann-Whitney U , bermakna jika p $<0,05$ 
dibandingkan kelompok kontrol dimana perubahan dinamika kadar IL-1 $\beta$ sangat terlihat perbedaan pada jam ke 2 pasca bedah. Hal ini dapat diasumsikan bahwa pemberian parecoxib pada analgesia epidural mampu menekan kadar IL-1 $\beta$ secara konsisten pada jam ke 2 pasca bedah dibandingkan dengan epidural tunggal yang tidak mampu menekan lonjakan IL-1 $\beta$ pada jam ke 2 pasca bedah.

Penelitian ini mendukung penelitian sebelumnya bahwa penggunaan analgesia epidural dan COX-2 selektif inhibitor dapat menekan sitokin proinflamasi dimana jika tidak terjadi sensitisasi sentral maka kadar IL-1 $\beta$ dapat dicegah peningkatannya.

Pada hasil penelitian ini di dapatkan NRSI sebelum dan pascabedah tidak berbeda antara dua kelompok ( $p>0,05)$. Sehingga dapat dikatakan secara klinis pada waktu pengamatan yaitu prabedah, 2 dan 24 jam pascabedah tidak ada perbedaan intensitas nyeri saat istirahat. Namun bila diamati lebih lanjut terjadi beberapa perbedaan klinis dalam rentang waktu 24 jam pascabedah diantara 2 kelompok, perbedaan pertama adalah NRSB 24 jam pascabedah $(\mathrm{p}<0,05)$, pada Kelompok Parecoxib tidak didapatkan alodinia namun di Kelompok Kontrol terdapat alodinia pada jam ke-24 ( $\mathrm{p}<0,05)$, yang kedua adalah perbedaan konsumsi analgetik epidural antara 2 kelompok, Kelompok Kontrol memiliki konsumsi analgetik epidural lebih besar $(p<0,05)$ dibandingkan Kelompok Parecoxib, yang ketiga adalah proporsi pasien yang memerlukan rescue lebih banyak pada Kelompok Kontrol dibandingkan Kelompok Parecoxib $\quad(\mathrm{p}<0,05)$, selanjutnya adalah waktu pemberian rescue pertama pada kelompok kontrol juga lebih cepat dibanding kelompok Parecoxib. Hal ini membuktikan bahwa parecoxib $40 \mathrm{mg}$ IV yang dikombinasi dengan analgesia epidural lebih superior dibandingkan plasebo.

Hasil penelitian ini sejalan dengan penelitian yang dilakukan oleh $\mathrm{Xu}$ et al. (2010), Buvanandran et al. (2003), dan Esme et al.(2011) bahwa pemberian COX-2 inhibitor memiliki intensitas nyeri yang lebih rendah dibanding grup kontrol, perbedaannya adalah penelitian ini membandingkan antara intensitas nyeri saat istirahat dan bergerak.

Tidak adanya perbedaan yang bermakna antara NRSI dan NRSB pada Kelompok Parecoxib sesuai dengan teori yang menyatakan bahwa pemberian COX-2 inhibitor yang bekerja sentral dapat mencegah terjadinya sensitisasi sentral melalui hambatan PGEs baik perifer maupun sentral. Adanya respon inflamasi akibat kerusakan jaringan pascabedah sensitif terhadap blokade neural oleh anestetik lokal maupun terhadap COX inhibitor yang bekerja perifer, namun sinyal inflamasi yang beredar di sirkulasi sitemik dan menginduksi sebaran COX-2 di SSP tidak efektif semata-mata di tekan oleh anestesi regional sehingga dibutuhkan kombinasi dengan COX-2 inhibitor yang bekerja sentral agar dapat secara 
optimal mengurangi nyeri pascabedah dan respon stres pascabedah.

\section{SIMPULAN}

Kombinasi epidural bupivakain 0,125\% dengan parecoxib $40 \mathrm{mg}$ mengurangi intensitas nyeri pascaoperasi dan dapat mengurangi kebutuhan analgetik epidural maupun analgetik tambahan serta dapat menurunkan kadar IL-1 $\beta$ pasca operasi.

\section{DAFTAR PUSTAKA}

1. Apfelbaum JL, Chen C, Mehta SS, Gan TJ. Postoperatif pain experience: result from a national survey suggest postoperatif continues to be undermanage. Anesth Analg. 2003; 97(2) ):534-40

2. Reuben S, Buvanendran A. The role of preventive multimodal analgesia and impact on patient outcome. In: Sinatra RS, LeonCasasola OAd, Ginsberg B, Viscusi ER, McQuay H, editors. Acute pain management. 1st ed. 2009; New York: Cambridge University Press. p. 172-83.

3. Ashburn MA, Caplan RA, Carr DB. Practice guidelines for acute pain management in the perioperative setting: an updated reported by the American Society of Anesthesiologiest task force on acute pain management. Anesthesiology. 2004; 100:1573-81.

4. Ahmad M.R. Peran analgesia epidural preemtif terhadap intensitas nyeri, respon hemodinamik serta dinamika kadar sitokin proinflamasi dan antiinflamasi pada pasca bedah ekstremitas bawah [Disertasi]. 2012; Makassar: Universitas Hasanuddin.
5. Samad TA, Sapirstein AA, Woolf CJ. Prostanoid and pain : unraveling mechanism and revealing therapetic targets. Trens Mol Med. 2012; 8:390-96.

6. Beilin B, Bessler H, Mayburd E, Smirnov G, Dekel A. Effect of preemtive analgesia on pain and cytokine production in postoperative period. Am Societ Anesth. 2003; 98:151-55.

7. Brandsborg B, Dueholm M, Jensen TS. Nikolajsen L. Mechanosensitivity before and after hysterecyomy: a prospective study on the prediction of acute and chronic postoperative pain. Br J Anest. 2011; 9:1-8.

8. Barton SF, Langeland FF, Snabes MC, LeComte D, Kuss ME. Efficacy and safety of intravenous parecoxib sodium in relieving acute postperative pain following gynecologic laparotomy surgery. Anesthesiology. 2002; 97:306-14.

9. Ng A, Smith G, Davidson AC. Analgesic effects of parecoxib following total abdominal hysterectomi.Br J Anaesth. 2003; 90(6):746-9.

10. Malan TP, Gordon S, Hubbard R, Snabes M. The cyclooxygenase- 2 spesific inhibitor is effective as $12 \mathrm{mg}$ of morphine administered intramuscularly for treating pain after gynecologic laparotomy. Anest Analg. 2005; 100:454-60.

11. Naito Y, Tamai S, Shingu K, Matsui T, Segawa H. Responses of plasma adrenocotricotropic hormone, cortisol, and cytokines during and afterupper abdominal surgery. Anesthesiology. 1992; 77(3):426-31.

12. Aida S, Baba H, Yamakura T, Taga K, Fukuda S , Shimoji K. The effectiveness of preemtive analgesia variies according to the type of surgery: a randomized, double-blind study. Anesth Analg. 1999; 89:711-16. 